\title{
Influence of biofilm composition on the resistance to detachment
}

\author{
M. Simões ${ }^{1}$, S. Cleto ${ }^{1}$, M. O. Pereira ${ }^{1}$, M. J. Vieira ${ }^{1}$ \\ ${ }^{1}$ Centro de Engenharia Biológica - CEB, Universidade do Minho, 4710-057 Braga, \\ Portugal \\ (E-mail: mjvsimoes@deb.uminho.pt; sara.cleto@gmail.com; mopereira@ deb.uminho.pt; mjv@deb.uminho.pt)
}

\begin{abstract}
Bacillus cereus and Pseudomonas fluorescens were used to develop monoculture biofilms in a bioreactor rotating system using a stainless steel cylinder for biofilm formation. The biofilms were allowed to grow for $7 \mathrm{~d}$ exposed continuously to a Reynolds number of agitation $\left(\operatorname{Re}_{\mathrm{A}}\right)$ of 2400. Afterwards, the biofilms were characterized in terms of respiratory activity, amount of biomass, cellular density, cellular size and total and extracellular proteins and polysaccharides. The biofilm mechanical stability was assessed by sequential submission of the biofilms to increasing $\mathrm{Re}_{\mathrm{A}}$, respectively, 4000, 8100, 12100 and 16100. The results showed that P. fluorescens biofilms were 5 times more active, had a higher amount of biomass, cellular density, a reduced cellular size and a four-fold higher amount of extracellular proteins and polysaccharides than $B$. cereus biofilms. The application of shear stress forces higher than the one under which the biofilm was formed $\left(\operatorname{Re}_{\mathrm{A}}=2400\right)$ caused biomass removal. The high percentage of removal occurred with the implementation of a $\operatorname{Re}_{\mathrm{A}}$ of 8100 for both $B$. cereus and $P$. fluorescens biofilms. The total series of $\operatorname{Re}_{\mathrm{A}}$ did not give rise to total biofilm removal, since only about $76 \%$ of $P$. fluorescens biofilm mass and $53 \%$ of $B$. cereus biofilm mass were detached from the cylinders. This latter result evidences that $B$. cereus had a higher mechanical stability than $P$. fluorescens biofilms. The overall results demonstrate that $P$. fluorescens and $B$. cereus formed physiological distinct biofilms, being $B$. cereus biofilms mainly constituted by cells and $P$. fluorescens biofilms vastly constituted by extracellular proteins and polysaccharides. B. cereus biofilms had a substantial higher mechanical stability than $P$. fluorescens biofilms.
\end{abstract}

Keywords: Biofilm behaviour; Biofilm control; Mechanical stability; Mechanical stress; Phenotypic characterization

\section{Introduction}

A better understanding of biofilm behaviour is particularly important due to the many serious problems associated with their presence (Simões et al. 2003). Once developed, biofilms are harder to be removed completely (Simões et al. 2003; 2005a). Mechanical forces is a parameter often involved simultaneously in the sanitation and removal of biofilms, since the application of sole chemical agents tends to leave the biofilm intact when no mechanical treatment is implemented in the control process (Simões et al. 2005a). Furthermore, physical forces acting on the biofilm influence the biofilm structure (Pereira et al. 2002; Stoodley et al. 1999; Vieira et al. 1993).

An important biofilm feature involved in the recalcitrance to current biofilm control procedures is the mechanical stability. This biofilm parameter, i.e., the behaviour of biofilms face to external stress mechanical conditions, is an important factor in determining the structure and function of biofilm systems, playing a key role in the removal and/or control of biofilms in engineered systems (Poppele and Hozalski, 2003, Simões et al. 2005a). So far, very limited studies have been done regarding the mechanical stability of biofilms (Ohashi and Harada, 1994; 1996; Ohashi et al. 1999; 
Stoodley et al. 1999; Körstgens et al. 2001; Poppele and Hozalski, 2003; Simões et al. 2005a).

According to Körstgens et al. (2001), the EPS matrix provides the biofilm mechanical stability by filling and forming the space between the bacterial cells, keeping them together. The biofilm matrix develops an inherent internal tension, which is in equilibrium with the shear stress under which the biofilm is formed and the removal of a well established biofilm requires the overcome of the forces which maintain the integrity of the biofilm (Stoodley et al. 1999; Körstgens et al. 2001). Several authors also reported that EPS production is required for biofilm formation (initial attachment) and development (Danese et al. 2000; Watnick and Kolter, 1999). Furthermore, the biofilm matrix structure, function and composition varies greatly depending on the microbial cells and the prevailing environmental conditions (Rättö et al. 2005).

In this study, biofilms formed by $B$. cereus, a Gram positive bacteria and $P$. fluorescens, a Gram negative bacteria, were developed in a bioreactor rotating system that allows the formation and subsequent exposure of biofilms to different mechanical stresses. With this system, it was possible to characterize the developed biofilms and to assess the intrinsic biofilm mechanical stability.

\section{Materials and Methods}

Microorganism and Culture conditions

Pseudomonas fluorescens (ATCC $13525^{\mathrm{T}}$ ) was obtained from the American Type Culture Collection. Bacillus cereus was isolated from a disinfection solution and identified by $16 \mathrm{~S}$ ribosomal DNA sequence analysis.

Bacterial growth was performed in a $0.5 \mathrm{~L}$ chemostat aerated, agitated, and continuously fed $(10 \mathrm{~mL} / \mathrm{h})$ with growth media consisting of $5 \mathrm{~g} / \mathrm{L}$ glucose, $2.5 \mathrm{~g} / \mathrm{L}$ peptone and $1.25 \mathrm{~g} / \mathrm{L}$ yeast extract, in phosphate buffer at pH 7 (Simões et al. 2005a).

\section{Biofilm reactor system and operation}

Biofilms were grown on ASI 316 stainless steel cylinders, with a surface area of 34.6 $\mathrm{cm}^{2}$ (diameter $=2.2 \mathrm{~cm}$; length $=5 \mathrm{~cm}$ ), inserted in a $3.5 \mathrm{~L}$ reactor and rotating at a constant Reynolds number of agitation $\left(\mathrm{Re}_{\mathrm{A}}\right)$ of 2400 . Three stainless steel cylinders were used in every experiment. This reactor was continuously fed $(1.7 \mathrm{~L} / \mathrm{h})$ with sterile diluted medium, containing $50 \mathrm{mg} / \mathrm{L}$ glucose, $25 \mathrm{mg} / \mathrm{L}$ peptone, $12.5 \mathrm{mg} / \mathrm{L}$ yeast extract

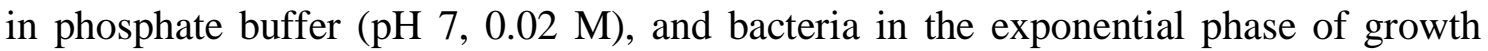
supplied by the above referred $0.5 \mathrm{~L}$ chemostat at a flow rate of $10 \mathrm{~mL} / \mathrm{h}$. The biofilms were allowed to grow for $7 \mathrm{~d}$ in order to obtain steady-state biofilms (Pereira et al. 2001).

\section{Biofilm scraping}

The biofilm that covered the metal slides was entirely removed from the slides, using a stainless steel scraper and then resuspended into $10 \mathrm{~mL}$ of extraction buffer $(2 \mathrm{mM}$ $\mathrm{Na}_{3} \mathrm{PO}_{4}, 2 \mathrm{mM} \mathrm{NaH}{ }_{2} \mathrm{PO}_{4}, 9 \mathrm{mM} \mathrm{NaCl}$ and $\left.1 \mathrm{mM} \mathrm{KCl}, \mathrm{pH} 7\right)$ and homogenised in a vortex (Heidolph, model Reax top) for $30 \mathrm{~s}$ with $100 \%$ power input, according to the methodology described by Simões et al. (2005a). Homogenised biofilm suspensions were then used to assess, sequentially, respiratory activity, cellular density, cellular size, proteins and polysaccharides content and mass.

The experiments were repeated in three different occasions by performing three independent biofilm formation experiments. 


\section{Biofilm matrix extraction}

Extraction of the extracellular components of the biofilm was carried out using Dowex resin (50X 8, $\mathrm{NA}^{+}$form, 20-50 mesh, Aldrich-Fluka 44445) according to the procedure described by Frølund et al. (1996). The biofilms were resuspended in $20 \mathrm{~mL}$ of extraction buffer and $50 \mathrm{~g}$ of Dowex resin per $\mathrm{g}$ of volatile solids were added to the biofilm suspension and the extraction took place at $400 \mathrm{~min}^{-1}$ for $4 \mathrm{~h}$ at $4{ }^{\circ} \mathrm{C}$. The extracellular components were separated from the cells through centrifugation $(3777 \mathrm{~g}$, 5 min).

\section{Respiratory activity assessment}

The respiratory activity of the biofilm was evaluated by measuring oxygen uptake rates due to glucose consumption in a biological oxygen monitor (BOM) in short-term assays. The assays were performed in a Yellow Springs Instruments BOM (Model 53) and the procedure used was described elsewhere (Simões et al. 2005b).

\section{Direct cell counts}

After the extraction procedure the cells separated from the extracellular products were diluted to an adequate concentration, being thereafter stained with 4,6-diamidino-2phenylindole - DAPI (Sigma Cat. No. D-9542) as described by Saby et al. (1997) and inspected by epifluorescence microscopy. A program path (Sigma Scan Pro 5, Sigma) involving object measurement and data output was used to assess the cellular size and to quantify the number of cells.

\section{Proteins and polysaccharides}

The proteins were determined by the Lowry modified method using bovine serum albumin as standard (Sigma, Portugal, Cat. No. P5656) and the polysaccharides by the phenol-sulphuric acid method of Dubois et al. (1956) using glucose as standard.

\section{Biofilm mass quantification}

The wet biofilm mass was assessed by the difference between the cylinder plus biofilm before the treatment and the clean cylinder.

The dry biofilm mass was assessed by the determination of the total volatile solids (TVS) of the homogenised biofilm suspensions, according to the Standard Methods (1989), method number 2490 A-D. The biofilm mass accumulated was expressed in $g$ of TVS per $\mathrm{cm}^{2}$ of surface area of the stainless steel cylinder.

\section{Mechanical stability of the biofilm}

This parameter was investigated by biomass loss after submitting the biofilms covered the stainless steel cylinders to increasing $\mathrm{Re}_{\mathrm{A}}$, according to the methodology described by Simões et al. (2005a). After $7 \mathrm{~d}$ of operation, the cylinders plus biofilm were removed from the reactor. After that, the cylinders were weighed, introduced in reactors $(170 \mathrm{~mL})$ with phosphate buffer, and consecutively subjected to serial $\operatorname{Re}_{\mathrm{A}}$, i.e., 4000 , 8100,12100 , and 16100 , for a period of $30 \mathrm{~s}$ each. The wet weight of the cylinders plus biofilm attached was ascertained before and after each $\mathrm{Re}_{\mathrm{A}}$. The wet mass of the biofilm removed from the cylinder surface, after each $\mathrm{Re}_{\mathrm{A}}$, was expressed in percentage of biofilm removal, and the biofilm that stayed adhered on the cylinders after the serial $\mathrm{Re}_{\mathrm{A}}$ was expressed as percentage of biofilm remaining. 
Statistical analysis

The mean and standard deviation within samples were calculated for all cases. The statistical software package SPSS 14.0 was used for statistical analysis. The results were statistically tested by using a parametric test (one-way analysis) when data were normally distributed as assessed by the Levene`s test of homogeneity. Nonparametric statistical tests (Mann-Whitney or Krustal-Wallis) were used for data that were not normally distributed. Statistical calculations were based on confidence level equal or higher than $95 \%$.

\section{Results and Discussion}

Characterization of the B. cereus and P. fluorescens biofilms formed on the bioreactor rotating system

Some characteristics of the B. cereus and P. fluorescens biofilms formed on the cylinders of the bioreactor rotating device, namely the biofilm activity, cellular density, cellular size, mass, protein and polysaccharide content, are presented in Table 1.

Table 1 Characteristics of the B. cereus and P. fluorescens biofilms formed on the surface of the stainless steel cylinders after $7 \mathrm{~d}$ of growth

\begin{tabular}{cccc}
\cline { 2 - 3 } & & B. cereus & P. fluorescens \\
\hline $\begin{array}{c}\text { Biofilm activity } \\
\left(\mathrm{mg} \mathrm{O}_{2} / \mathrm{g}_{\text {biofilm.min }}\right)\end{array}$ & $0.0332 \pm 0.0098$ & $0.150 \pm 0.022$ \\
\multicolumn{2}{c}{ Cellular density $\left(\mathrm{cells} / \mathrm{cm}^{2}\right)$} & $1.03 \times 10^{13} \pm 2.1 \times 10^{12}$ & $9.88 \times 10^{13} \pm 3.3 \times 10^{12}$ \\
Cellular size $(\mu \mathrm{m})$ & $1.58 \pm 0.09$ & $0.583 \pm 0.07$ \\
Biofilm mass & Dry & $0.413 \pm 0.11$ & $0.907 \pm 0.093$ \\
$\left(\mathrm{mg} / \mathrm{cm}^{2}\right)$ & Wet & $13.2 \pm 0.10$ & $21.5 \pm 6.1$ \\
Proteins & Total & $205 \pm 27$ & $210 \pm 19$ \\
$\left(\mathrm{mg} / \mathrm{g}_{\text {biofilm }}\right)$ & Extracellular & $15.8 \pm 5.3$ & $59.9 \pm 15$ \\
Polysaccharides & Total & $307 \pm 33$ & $200 \pm 4.6$ \\
$\left(\mathrm{mg} / \mathrm{g}_{\text {biofilm }}\right)$ & Extracellular & $30.3 \pm 4.2$ & $121 \pm 56$ \\
\hline
\end{tabular}

The bioreactor rotating system allowed the formation of a high amount of biofilm by $B$. cereus and $P$. fluorescens that covered the surface of the stainless steel cylinders (results not shown). From Table 1 it can be verified that $B$. cereus and P. fluorescens biofilms were metabolically active, since they showed the ability to oxidize glucose (Simões et al. 2005b), and contained about $96-97 \%$ of water, which is in accordance with other authors (Vieira et al, 1993; Pereira et al. 2001). P. fluorescens biofilms were 5 times more active, had a higher amount of biomass ( 2 times), cellular density (about $1 \mathrm{log}$ ), a reduced cellular size (when comparing with the planktonic situation - results not shown) and a four-fold higher amount of extracellular proteins and polysaccharides than B. cereus biofilms.

The amount of extracellular proteins was about $9 \%$ and $29 \%$ of the total biofilm proteins and the amount of extracellular polysaccharides was nearly $11 \%$ and $61.5 \%$ of the total biofilm polysaccharides, respectively for biofilms formed by $B$. cereus and $P$. fluorescens. This result reveals that the matrix of $P$. fluorescens biofilms was highly composed by proteins and polysaccharides. The amount of EPS plays a significant role 
in the recalcitrance of biofilms, as the EPS strength the cohesive forces within the biofilm, thereby contributing to an enhanced inherent biofilm mechanical stability (Azeredo and Oliveira, 2000).

The characteristics of the $P$. fluorescens biofilms formed on the stainless steel cylinders (Table 1), namely the respiratory activity, biofilm mass and total content of proteins and polysaccharides, are similar to the ones observed in biofilms formed in a flow cell system under turbulent flow (Simões et al. 2005c), specifically the significant content of extracellular proteins and polysaccharides found in the composition of the biofilm matrix. Regarding B. cereus biofilms, no previous studies are available in terms of phenotypic characterization. In fact, according to Kolari et al. (2001), B. cereus is an inefficient biofilm former. However, this study reveals the biofilm formation ability of B. cereus when using bioreactors that mimic real industrial situations. Furthermore, it is known that no strain can effectively represent its species (Fux et al. 2005).

Monoculture B. cereus and P. fluorescens biofilms formed in a chemostat, according to the procedure described by Simões et al. (2003), were inspected by scanning electron microscopy (SEM) and the results are depicted in Fig. 1.
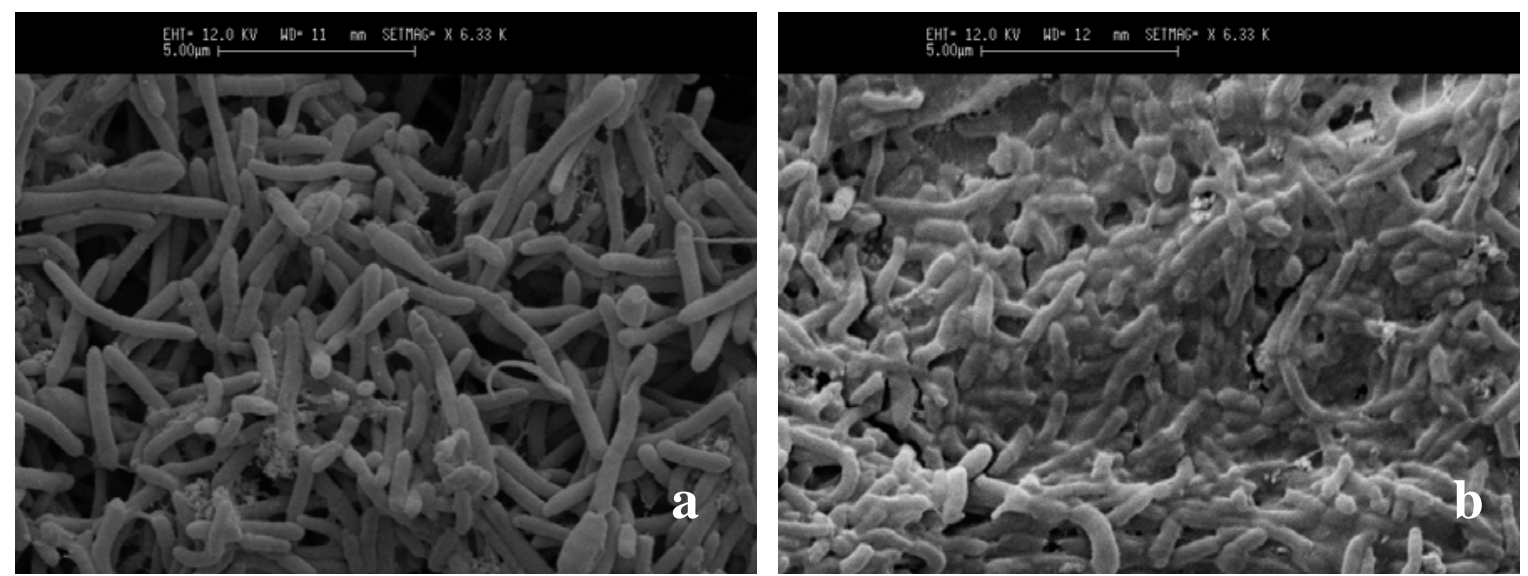

Fig. 1 SEM photomicrographs of a 6 old $B$. cereus (a) and P. fluorescens (b) and biofilms formed on stainless steel slides. Magnification $\times 6330$, bar $=5 \mu \mathrm{m}$.

The existence of a more complex matrix of $P$. fluorescens biofilms when compared with the one existent in $B$. cereus biofilms is evident when visualizing the biofilms by SEM (Fig. 1). This microscopic evidence corroborates the extracellular proteins and polysaccharides results found in Table 1. The biofilm matrix acquired great importance in the biofilm architecture, and thus in biofilm mechanical stability, as EPS are responsible for keeping biofilm together and binding the biofilm to the support, forming a temporary network of fluctuating junction points (Körstgens et al. 2001).

\section{Biofilm removal due to mechanical stress}

Fig. 2 shows the biofilm removal obtained due to the increase in the Reynolds number of agitation $\left(\mathrm{Re}_{\mathrm{A}}\right)$ for $B$. cereus and $P$. fluorescens biofilms developed on the stainless steel cylinder. 


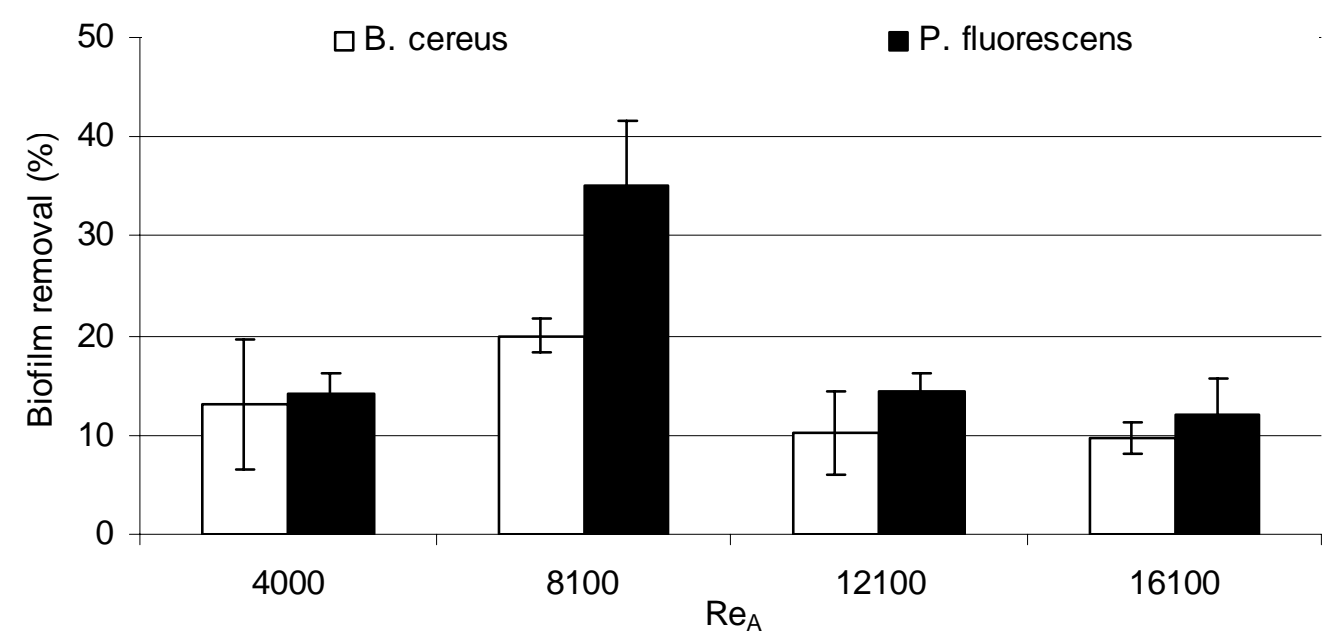

Fig. 2 Biofilm removal for the control assay due to change in the $\operatorname{Re}_{\mathrm{A}}$.

In this study the mechanical stability of the biofilm was assessed by submitting biofilms to different shear stress forces, correspondent to increasing $\mathrm{Re}_{\mathrm{A}}$. The existence of shear stress forces higher than the one under which the biofilm was formed $\left(\operatorname{Re}_{\mathrm{A}}=2400\right)$ caused biofilm removal. This mechanical stability experiment (Fig. 2) shows that biofilms subjected to mechanical treatment were hardly removed with low shear stress $\left(\operatorname{Re}_{\mathrm{A}} \leq 4000\right)$ since only about $13 \%$ (B. cereus) and $14 \%$ (P. fluorescens) of biofilm removal was achieved. However, when the $\operatorname{Re}_{\mathrm{A}}$ were raised from 4000 to 8100 a noticeable biofilm detachment was observed, but a layer remained on the surface even when the highest $\operatorname{Re}_{\mathrm{A}}$ was applied. In a biofilm control process, this biofilm remaining can act as an additional source of nutrients and/or as a suitable surface to further growth of cells (Simões et al. 2005c). The high percentage of removal occurred with the implementation of a $\operatorname{Re}_{\mathrm{A}}$ of 8100 for both biofilms (Fig. 2), being biofilm removal similar for the others Reynolds number tested $(P>0.05)$. So, it can be said that the biofilm removal is dependent on the hydrodynamic conditions $(P<0.05)$. Azeredo and Oliveira (2000) reported that biofilm detachment is processed in layers, where the increase in the shear stress may progressively thin the biofilm, being mechanical failure and total detachment the ultimate effect expected. Fig. 2 also shows that the total series of $\mathrm{Re}_{\mathrm{A}}$ number did not give rise to total biofilm removal.

The total percentage of biofilm that was not removed by the submission to the total series of $\mathrm{Re}_{\mathrm{A}}$, considered as the biofilm remaining, is presented in Table 2 .

Table 2 Total percentage of $B$. cereus and P. fluorescens biofilm remaining on the stainless steel surface after the submission to the total series of $\operatorname{Re}_{\mathrm{A}}$

\begin{tabular}{ccc}
\cline { 2 - 3 } & B. cereus & P. fluorescens \\
\hline Biofilm remaining (\%) & $47.0 \pm 7.5$ & $24.2 \pm 5.3$ \\
\hline
\end{tabular}

From Table 2 it is possible to ascertain that $47 \%$ of the total B. cereus biofilms and 24 $\%$ of the $P$. fluorescens biofilms remained adhered to the stainless steel surface, after submission to the total series of $\operatorname{Re}_{\mathrm{A}}$. This result demonstrates that $B$. cereus biofilms had a higher mechanical stability than biofilms formed by $P$. fluorescens. The comparison between biofilm composition (Table 1) and mechanical stability results (Fig. 2 and Table 2) proposes that other molecular mechanisms besides the EPS amount, such as quorum sensing phenomenon and EPS composition can account for the distinct 
behaviour of $B$. cereus and $P$. fluorescens biofilms face to mechanical stress. For example, the existence of quorum sensing events is known to be expressed differently by Gram negative and Gram positive bacteria (El-Sayed et al. 2001; Dong et al. 2002), playing an important role the biofilm formation and behaviour (Davies et al. 1998). Also, microbial binding strength to surfaces depends on the chemical nature of the EPS (Perry IV et al. 2005). This preliminary study suggests that further analyses are required in order to ascertain the basis of the increased mechanical stability of B. cereus biofilms.

\section{Conclusions}

The system presented in this work provided an reliable approach to investigate the mechanical stability of biofilms, leading to a better understanding of biofilms in different environments and the development of biofilm control strategies. The characterization of the biofilms showed that the system tested allowed to the formation of a great amount of $B$. cereus and $P$. fluorescens biofilms that covered the surface of the stainless steel cylinders and having an inherent mechanical stability. B. cereus and $P$. fluorescens formed physiological distinct biofilms, being $B$. cereus biofilms mainly constituted by cells while $P$. fluorescens biofilms were vastly constituted by EPS. The evidence of the more complex $P$. fluorescens biofilm matrix did not played a major role on the maintenance of the biofilm mechanical stability as proposed on previous studies (Stoodley et al. 1999; Körstgens et al. 2001; Poppele and Hozalski, 2003). In fact, $B$. cereus biofilms with a smaller content of EPS had a higher mechanical stability than $P$. fluorescens biofilms.

\section{Acknowledgments}

The authors acknowledge the financial support provided by IBQF, and the Portuguese Foundation for Science and Technology (Project CHEMBIO - POCI/BIO/61872/2004 and Post-Doc Grant - Manuel Simões).

\section{References}

Azeredo J. and Oliveira R. (2000). The role of exopolymers produced by Sphingomonas paucimobilis in biofilm formation and composition. Biofouling 16, 17-27.

Danese P. N., Pratt L. A. and Kolter R. (2000). Exopolysaccharide production is required for development of Escherichia coli K-12 biofilm architecture. J. Bacteriol. 182, 3593-3596.

Davies D. G., Parsek M. R., Pearson J. P., Iglewski B. H., Costerton J. W. and Greenberg E. P. (1998). The involvement of cell-to-cell signals in the development of a bacterial biofilm. Science 280, 295-298.

Dong Y.-H., Gusti A. R., Zhang Q., Xu J-L. and Zhang L.-H. (2002). Identification of quorum-quenching $\mathrm{N}$-acyl homoserine lactonases from Bacillus species. Appl. Environ. Microbiol. 68, 1754-1759.

Dubois M., Gilles K. A., Hamilton J. K., Rebers A. and Smith F. (1956). Colorimetric method for determination of sugars and related substances. Anal. Chem. 28, 350-356.

El-Sayed A. K., Hothersall J. and Thomas C. M. (2001). Quorum-sensing-dependent regulation of biosynthesis of the polyketide antibiotic mupirocin in Pseudomonas fluorescens NCIMB 10586. Microbiology 147, 2127-2139.

Frølund B., Palmgren R., Keiding A. and Nielsen P.H. (1996). Extraction of extracellular polymers from activated sludge using a cation exchange resin. Water Res. 30, 1749-1758.

Fux C. A., Shirtliff M., Stoodley P. and Costerton J. W. (2005). Can laboratory reference strains mirror "real-world" pathogenesis. Trends Microbiol. 13, 58-63. 
Kolari M., Nuutinen J. and Salkinoja-Salonen M. S. (2001). Mechanisms of biofilm formation in paper machine by Bacillus species: the role of Deinococcus geothermalis. J. Ind. Microbiol. Biotechnol. 27, 343-351.

Körstgens V., Flemming H.-C., Wingender J. and Borchard W. (2001). Uniaxial compression measurement device for investigation of the mechanical stability of biofilms. J. Microbiol. Meth. 46, 9-17.

Ohashi A. and Harada H. (1994). Adhesion strength of biofilm developed in an attached-growth reactor. Wat. Sci. Tech. 29, 281-288.

Ohashi A. and Harada H. (1996). A novel concept foe evaluation of biofilm adhesion strength by applying tensile force and shear force. Wat. Sci. Tech. 34, 201-211.

Ohashi A., Koyama T., Syutsubo S. and Harada H. (1999). A novel method for evaluation of biofilm tensile strength resisting erosion. Wat. Sci. Tech. 39, 261-268.

Pereira M. O., Morin P., Vieira M. J. and Melo L. F. (2001). A versatile reactor for continuous monitoring of biofilm properties in laboratory and industrial conditions. Lett. Appl. Microbiol. 34, 22-26.

Pereira M. O. Kuehn M., Wuertz S., Neu T. and Melo L. (2002). Effect of flow regime on the architecture of a Pseudomonas fluorescens biofilm. Biotech. Bioeng. 78, 164171.

Perry IV T. D., Klepac-Cera-J V., Zhang X. V., McNamara C. J., Polz M. F., Martin S. T. Berke N. and Mitchell R. (2005). Binding of harvested bacterial exopolymers to the surface of calcite. Environ. Sci. Technol. 39, 8770-8775.

Poppele E. H. and Hozalski R. M. (2003). Micro-cantilever method for measuring the tensile strength of biofilms and microbial flocs. J. Microbiol. Meth. 55, 607-615.

Rättö M., Suihko M.-L. and Siika-aho M. (2005). Polysaccharide-producing bacteria isolated from paper machine slime deposits. J. Ind. Microbiol. Biotechnol. 32, 109-114.

Saby S., Sibille L., Mathiew J., Paquin L. and Block J. C. (1997). Influence of water chlorination on the counting of bacteria with DAPI (4, 6-diamino-2-phenylindole). Appl. Environ. Microbiol. 63, 1564-1569.

Simões M., Carvalho H., Pereira M. O. and Vieira M. J. (2003). Studies on the behaviour of Pseudomonas fluorescens biofilms after ortho-phthalaldehyde treatment. Biofouling 19, 151-157.

Simões M., Pereira M. O. and Vieira M. J. (2005a). Effect of mechanical stress on biofilms challenged by different chemicals. Water Res. 39, 5142-5152.

Simões M., Pereira M. O. and Vieira, M. J. (2005b). Validation of respirometry as a short-term method to assess the efficacy of biocides. Biofouling 21, 9-17.

Simões M., Pereira M. O. and Vieira M. J. (2005c). Action of a cationic surfactant on the activity and removal of bacterial biofilms formed under different flow regimes. Water Res. 39, 478-486.

Standard methods for the examination of water and wastewater (1989). 17 $7^{\text {th }}$ edn, American Public Health Association/American Water Works Association/American Environment Federation, Washington DC, USA.

Stoodley P., Boyle J. D., DeBeer D. and Lappin-Scott H. M. (1999). Evolving perspectives of biofilm structure. Biofouling 14, 75-90.

Vieira M. J., Melo L. and Pinheiro M. M. (1993). Biofilm formation: hydrodynamic effects on internal diffusion and structure. Biofouling 7, 67-80.

Watnick P. I. and Kolter R. (1999). Steps in the development of a Vibrio cholerae El Tor biofilm. Mol. Microbiol. 34, 586-595. 